\title{
The Effect of Computer Assisted Instruction According To Bruner's Cognitive Development Principles on 3rd Grade Geometry Course Achievement And Permanency Of Learned
}

\author{
Sıtkı ÇEKİRDEKCİ, Veli TOPTAŞ, Nergiz ÇEKİRDEKCİ
}

\section{Summary}

\section{PURPOSE}

The purpose of this research is to determine the effect of computer assisted instruction according to Bruner's cognitive development principles on 3rd grade students' achievement and permanence level of information which they have learned in the geometry learning field.

\section{METHOD}

In the process of obtaining data to the research, pretest-posttest control group semiexperimental design was used. The research was conducted with a public school 3rd grade students attending the two branches which providing training in Sultanbeyli district of Istanbul province in the fall semester of the 2015-2016 academic year. The total 73 students in experimental group 36 and control group 37 participated to the study. The total 73 students including in experimental group 36 and control group 37 participated the study. The geometry achievement test which was developed by the researchers and consist of 19 question were used as a data collection tool. In the analysis process; Kolmogorov-Smirnov test, Independent Samples T-Test, Paired Samples T-Test and Ancova was used. Significance was evaluated at the level of .05.

\section{FINDINGS}

In the research the arithmetic mean of the pretest scores between the experimental and control groups weren't statistically significant differences ( $p>.05)$. The arithmetic mean of the post-test scores between the experimental and control groups were statistically significant differences $(\mathrm{p}<.05)$. The corrected permanence test scores according to the post-test scores between the experimental and control group were statistically significant differences $(p<.05)$. As a result of the study, computer assisted instruction according to Bruner's cognitive development principles had a positive impact to increase the success of students. But this method didn't affect the permanence of the knowledge. 